\title{
CONSTRUÇÃO SOCIAL DA NOÇÃO DE COMUM E A REFORMA AGRÁRIA NO ESTADO DO RIO DE JANEIRO: UM ESTUDO DE CASO'
}

\author{
Rodolfo Bezerra de Menezes Lobato da Costa²
}

\begin{abstract}
Resumo
Neste artigo pretendemos identificar as construções sociais da noção de "comum" a partir de um estudo de caso: o projeto de assentamento rural Sebastião Lan II, localizado no município de Silva Jardim (RJ). Tomamos como referência a releitura das práticas sociais, políticas e estatais em relação à comunidade rural para compreender as manifestações do "comum", como "essencialização", "estatização" e "coatividade". A (re)produção do tecido social sintetizou ambiguidades e contradições, por vezes inconscientes, de formas diferenciadas do "comum".

Palavras-chave: Sebastião Lan, assentamentos rurais, comum, conflitos socioambientais, acampamento rural.

\section{CONSTRUCCIÓN SOCIAL DE LA NOCIÓN COMÚN Y REFORMA AGRARIA EN EL ESTADO DE RÍO DE JANEIRO: UN ESTUDIO DE CASO}

\section{Resumen}

En este artículo pretendemos identificar las construcciones sociales de la noción de "común" a partir de un estudio de caso: el proyecto de asentamiento rural Sebastião Lan II, ubicado en el municipio de Silva Jardim (RJ). Tomamos como referencia la relectura de las prácticas sociales, políticas y estatales en relación con la comunidad rural para comprender las manifestaciones de lo "común", como "esencialización", "nacionalización" y "co-actividad". La (re)producción del tejido social sintetizó ambigüedades y contradicciones, a veces inconscientes, en formas diferentes de lo "común".

Palabras clave: Sebastião Lan, asentamientos rurales, comun, conflitos socioambientales, campamento rural.

\section{SOCIAL CONSTRUCTION OF THE NOTION OF THE COMMON AND THE AGRARIAN REFORM IN THE STATE OF RIO DE JANEIRO: A CASE STUDY}

\section{Abstract}

In this article we intend to identify the social constructions of the notion of "common" from a case study: the rural settlement project Sebastião Lan II, located in the municipality of Silva Jardim (RJ). We take as reference the rereading of social, political and state practices in relation to the rural community to understand the manifestations of the "common", such as "essentialization", "nationalization" and "coactivity". The (re) production of the social fabric synthesized ambiguities and contradictions, sometimes unconscious, in different ways from the "common".

Key words: Sebastião Lan, rural settlements, common, social and environmental conflicts, rural camp.

1 Artigo recebido em 31/01/2020. Primeira avaliação em 18/02/2020. Segunda avaliação em 11/03/2020. Aprovado em 24/04/2020. Publicado em 22/05/2020.

DOI: https://doi.org/10.22409/tn.v18i36.38063

${ }^{2}$ Mestre e Doutor em Ciências Sociais e Jurídicas pelo Programa de Pós-graduação em Sociologia e Direito (PPGSD) da Universidade Federal Fluminense - Brasil. Professor do Departamento de Sociologia da Universidade Federal do Paraná (UFPR) - Brasil. E-mail: rodolfolobato@hotmail.com ORCID: 0000-0001-6304-3831. 


\section{1- Introdução}

A incessante luta pelo acesso à terra e pela manutenção do tecido social de uma comunidade rural podem nos revelar diferentes percepções sobre o que é "comum". O que a priori compreendemos como uma tensão entre os conflitos socioambientais e a reforma agrária, a posteriori, podemos identificar lógicas sociais e diferentes apropriações sobre a noção de "comum". Apropriações essas que, quando identificadas empiricamente, aparecerão neste artigo como "essencialização", "estatização" e "co-atividade".

Assim, reinterpretaremos as três manifestações da noção de "comum" num nível de abstração apenas possível em decorrência de uma pesquisa de longa duração. $O$ trabalho de campo foi realizado de forma intermitente entre os anos de 2002 e 2018, num território localizado entre os municípios de Casimiro de Abreu e Silva Jardim (RJ), a comunidade rural de Sebastião Lan II.

O longo tempo é uma das chaves para a compreensão deste texto, seja como técnica de pesquisa ou como estratégia para sobrevivência dessa comunidade. $O$ tempo não aparece como elemento secundário, mas central no distanciamento entre as perspectivas de direito e as formas de ação e organização mobilizadas para a manutenção da ocupação da terra. Revelaremos, nesse território, lógicas próprias que não poderiam ser enquadradas em nenhum regime jurídico da política de reforma agrária, mas que se encontra materializada em dinâmicas sociais de ingresso na comunidade, mais precisamente na forma em que se constrói uma percepção idiossincrática de "comum", a área do "sapê".

Através do desapego às formalidades e aos limites legais revelaremos saídas criativas para a manutenção do tecido social. Essa ação coletiva permitiu, por exemplo, a produção de alimentos onde antes os técnicos declaravam impropriedades do solo ou até ilegalidades. Mesmo sem a devida regularização fundiária, a comunidade tem a singularidade de integrar um conjunto de redes econômicas, religiosas e culturais. Em que pese sua precarização dentro da estrutura social abrangente, fundamentalmente por serem juridicamente acampados.

O Projeto de Desenvolvimento Sustentável (PDS), modelo de viabilização de sua reprodução como beneficiários da política de reforma agrária proposto, foi colocado como a única alternativa de viabilização do assentamento. Importante 
ressaltar que essa situação altera-se a partir de 2018, momento em que a regularização fundiária torna-se uma alternativa diante de um cenário institucional adverso. Mas o modelo de PDS, e a tentativa de implementação, colocava como uma questão sine qua non a "constituição de uma área comum".

A tradução, assimilação e/ou resistência aos diferentes discursos institucionais combina-se à tentativa dos trabalhadores rurais em se reproduzir como beneficiários da política de reforma agrária. Por esse ângulo, há um cruzamento entre as diferentes perspectivas sobre a noção de "comum", dentro de uma área em que seus agentes estão em mudança de posição social. Isto é, a fluidez desse cenário exigiu desses sujeitos recursos criativos e possivelmente "inventados" a partir de sua determinação social exótica (liminar).

De trabalhadores rurais sem-terra em luta pela reforma agrária, passaram a se constituir enquanto uma comunidade rural que vive a ambiguidade de ser reconhecida enquanto tal e é, simultaneamente, marginalizada dos principais processos decisórios dos quais são ou deveriam ser beneficiárias. As contradições entre a prática cotidiana e as normas legais para o processo de reforma agrária remetem a determinadas inovações quanto ao referencial teórico a ser utilizado.

Nesse sentido este artigo procura tecer relações entre debates contemporâneos sobre a noção de comum, em especial aqueles produzidos na tensão entre o mundo latino-americano e o europeu. A perspectiva crítica de uma lógica "estadocêntrica" em contraposição ao emergente movimento social camponês será aqui explorado através de Raquel Gutiérrez Aguilar e de Mina Trujillo (2019), que tem seu campo de pesquisa localizado no México. E, de uma perspectiva europeia, e com a ênfase nas mudanças de concepções sobre o "comum" em referência à formação do Estado Moderno, dialogaremos com Pierre Dardot e Christian Laval (2017).

Essa contradição entre o plano institucional/estatal e a dinâmica social emergente, apareceu e se constituiu com a presença da Universidade Federal Fluminense (UFF). Essa presença ocorreu através da atuação formalizada em projetos de pesquisa e de extensão universitária, na condição de uma assessoria sociojurídica, o que corresponde às práticas do Observatório Fundiário Fluminense (OBFF) e do GT Ecosocial ${ }^{3}$, núcleos de pesquisa e extensão, também vinculados ao Programa de Pós-Graduação em Sociologia e Direito.

\footnotetext{
${ }^{3}$ Coordenados pelos/as professores: Ana Maria Motta Ribeiro e Wilson Madeira Filho, respectivamente.
} 
Apesar da pesquisa ser conduzida ao longo de quase duas décadas, teve dois momentos e duas formas diferenciadas. Esse recorte faz-se necessário para que possamos compreender o lugar de pertencimento diante da comunidade, através das formas pelas quais foram sendo conduzidas as duas mais significativas modalidades de pesquisa-ação (BRANDÃO, 1981). As motivações de intervenção e a entrada nessa história colaboraram e interferiram na trajetória de luta da comunidade.

A primeira experiência aconteceu a convite do Incra. No ano de 2002, a universidade pública atuou como agente harmonizador de um conflito entre o Ibama e Incra. Para atender a essa demanda, a reitoria da UFF formou uma equipe, que formalizou o GT Ecosocial (UFF, 2007). A singularidade desse conflito refere-se ao fato de que o território de Sebastião Lan II está localizado na Zona de Amortecimento da Reserva Biológica de Poço das Antas. A relevância política dessa unidade de conservação, e a preservação do mico-leão-dourado, aparecem como um "sinal" para compreendermos os sentidos da burocracia e a própria indicação de PDS, no lugar de um assentamento convencional, para a comunidade de Sebastião Lan II. Enquanto universidade, nesta oportunidade realizamos o processo de gestação de um Laudo Multidisciplinar. O caráter da pesquisa e extensão desenvolvidas o tornaram indissociáveis dos seus efeitos políticos, que culminou com a assinatura de um Termo de Ajustamento de Conduta (TAC).

Depois, em 2013 (passados dez anos da primeira pesquisa), fomos novamente convidados a acompanhar a viabilização do projeto (PDS). O novo contato com o campo nos revelou a enorme resistência da comunidade à proposta, e a estranha descoberta de que algumas das indicações previstas no Laudo e no TAC não tinham sido encaminhadas. Descobrimos que não houve um efetivo debate para integrar a comunidade numa construção democrática para a definição do PDS.

Tempos depois, e sem que a parceria entre a UFF e o Incra se efetivasse, lideranças de Sebastião Lan II, organizadas através de uma Associação, procuraram - OBFF e o GT Ecosocial. Foi o momento da portaria que criou o PDS, sem as considerações sobre os efeitos "negativos" de tal projeto. De tal cenário entra em cena uma Ação Civil Pública contra o Incra através da Defensoria Pública da União, para garantir um processo de assentamento que respeitasse a trajetória de conquista da terra e os investimentos realizados ao longo de duas décadas de ocupação da área. 
Ao tentar descrever a trajetória de conquista da terra demonstraremos as diferentes manifestações da noção de "comum", que reforçaram ou limitaram os espaços democráticos e de uso para a reprodução do tecido social da comunidade rural de Sebastião Lan II. Iniciaremos o desenvolvimento do artigo com uma redefinição conceitual, em seguida apresentaremos as manifestações do "comum" como essencialização, estatização e co-atividade.

\section{2- Questões preliminares sobre a noção de comum}

De um ponto de vista teórico esse artigo se enquadra na problematização sobre as formas de intervenção do Estado na estruturação de processos sociais agrários. Assim, a operacionalização da noção de "comum" nas políticas públicas de reforma agrária e seus respectivos processos de mediação, seja por parte de agências estatais ou das comunidades rurais, exige uma mínima problematização. Tentaremos identificar a coexistência de diferentes racionalidades, aparentemente ambíguas, conquanto se deduza uma penetração do capitalismo ou modernização das relações sociais.

Seguindo um paradigma marxista, as classes sociais não se restringem a categorias econômicas, de tal forma que podemos identificar diferentes racionalidades presentes em frações de classes e grupos sociais. O território em disputa vem a sintetizar diferentes trajetórias de reprodução de famílias numa determinada diversidade espaço-temporal. Essa singularidade, uma ocupação de terras, torna mais complexa as possibilidades e perspectivas, possibilitando uma redefinição de categorias. Trabalhamos com referência à noção de classe social, mas dada a transitoriedade do objeto de pesquisa fez-se necessário recorrer a uma tradição gramsciana que identifica uma diversidade das situações de subalternidade ${ }^{4}$. Estamos diante de uma população, oriunda das periferias da região metropolitana do Rio de Janeiro, que já integra uma história de exclusão, reserva de mão-de-obra, de

\footnotetext{
4 "...a categoria subalterno é certamente mais intensa e mais expressiva que a simples categoria de trabalhador. O legado da tradição gramsciana, que nos vem por meio dessa noção, prefigura a diversidade das situações de subalternidade, a sua riqueza histórica, cultural e política. Induz-nos a entender a diversidade de concepções, motivos, pontos-de-vista, esperanças, no interior das diferentes classes e grupos subalternos. [...] Por isso mesmo, obriga-nos a fazer indagações sobre a reprodução ampliada da subalternidade, sobre a multiplicação diferenciada dos grupos subalternos." (Martins, 1989, p. 98)
} 
mercados temporários, cuja clandestinização do trabalho ou a semilegalização estão presentes em seu cotidiano.

Essa análise a respeito do conceito de subalternidade, não em contraposição mas em paralelo à noção de classe social, procura recompor as características de uma população em situação de transição social. As posições sociais e as lacunas a serem ocupadas pelos agentes passam a ser objeto de reflexão a respeito da relação entre o Estado e a sociedade. Em resumo, procuramos desconstruir uma noção de classe a-histórica, ou seja, como uma suposta entidade capaz de gerar um sistema de visões de mundo de impecável coesão interna, estruturalmente invariável - ou seja, pressupomos o devir.

Nesse sentido, nosso primeiro passo será o estudo da relação ideologicamente induzida de associar o "comum" ao "estatal", outra forma a-histórica de compreender processos sociais complexos. Nessa temática encontraremos os trabalhos de Dardot e Laval (2017). Esses autores, inicialmente, citam a noção aristotélica de "pôr em comum" (koinónein), uma noção grega que "pressupõe sempre reciprocidade entre os que participam de uma atividade ou compartilham um modo de vida" (DARDOT; LAVAL, 2017, p.26).

Os autores (op.cit.) sugerem que a noção contemporânea de "bem comum", diferente da antiga acepção grega, passou a incorporar três fases que reatualizaram o conceito de "comum" em categorias jurídico-econômicas: a primeira essencialmente teológica (proveniente de instituições políticas e religiosas); a segunda eminentemente jurídica (como reflexo do discurso economicista); e finalmente a terceira, que associa o "comum" a ideia de universal.

A noção de "comum", traduzida pelo direito romano, incorporou duas fases fundamentais para compreender a transição da noção grega, definida por Aristóteles como uma prática de reciprocidade. Dardot e Laval (2017) citam Cícero como evidência de que havia uma clara diferença entre a "coisa pública" (que se impõe a todos) e a "utilidade pública", que diz respeito aos interesses do Estado.

Seria inconcebível justificar todos os atos do Estado, o qual pode chegar a defender interesses específicos que se oponham à utilidade da sociedade: "São notáveis os casos em que se desdenha a aparência da utilidade pública diante da beleza moral". Essa oposição propriamente republicana não se encontra no conjunto da doutrina política romana e desaparecerá na época imperial. Aliás, deve-se ressaltar a relativa indistinção, que durará por longo tempo, entre utilidade comum e utilidade pública (utilitas publica): a coisa pública e as obrigações da sociedade humana (societas hominum) se 
confundem. [...] O público se opõe ao privado, como o comum se opõe ao próprio. [...] o termo "público" designa o que compete ao Estado como tal, a suas instituições e funções: o publicum é o tesouro do Estado, os bona publica são os bens do Estado. A doutrina política romana nos legou um termo que, embora remeta à comunidade de cidadãos, pôde ser utilizado para enaltecer e aumentar a dominação da instituição do Estado sobre os sujeitos políticos. (LAVAL; DARDOT, 2017, págs. 29-30)

Com o passar dos séculos a noção de "utilidade comum" passou a ser secundária em relação à "utilidade pública" ou do Estado, recriando uma oposição antes inexistente entre a utilidade pública e dos particulares: "A primeira direção tomada pela doutrina política romana é a estatização do comum. A segunda é sua espiritualização no contexto cristão" (LAVAL; DARDOT, 2017, p. P31). Temos, assim, uma evidência do movimento que transformará o Estado em "detentor do monopólio da vontade comum" (op. cit.). A substituição da "utilidade comum" pela "utilidade pública" vem a se tornar fundamental na era moderna, assim podemos reinterpretar as noções contratualistas de "bem comum" ou de "vontade geral".

$\mathrm{Na}$ releitura do "comum" podemos citar Karl Marx (s/d), quando apresenta o próprio Estado como uma possível estrutura burocrática completa, hierarquizando politicamente as disputas entre seus órgãos com vistas não a uma racionalidade burocrática, mas a uma hierarquização política que não perturbe o status quo. Quando a estrutura burocrática é "obrigada a proteger a generalidade imaginária do interesse particular" (MARX, s/d, p. 71), a análise marxista aproxima-se de uma percepção weberiana de um "segredo" guardado no seio de um idílico "interesse público". Assim, localizamos também em Weber, uma crítica da noção clássica de um direito público como uma abstração ${ }^{5}$.

Também desse ponto de vista, Laval e Dardot enfatizam um primeiro movimento: a "estatização do comum" (a "res publica como persona ficta, coisa abstrata encarnada ou representada por uma pessoa pública", Laval e Dardot, 2017, p. 32). Num segundo momento teríamos a "espiritualização do comum", sendo a Igreja a detentora do monopólio da definição de bem supremo (o "fim último da existência

\footnotetext{
5 "Somente a burocratização do Estado e do direito vê, em geral, também a possibilidade definitiva de uma rigorosa distinção conceitual entre uma ordem jurídica "objetiva" e os direitos "subjetivos" do indivíduo, por ela garantidos, do mesmo modo que a distinção entre o direito "público", referente às relações das autoridades entre si e com os "súditos", e o direito "privado", que regula as relações entre os indivíduos dominados. Esta pressupõe a distinção conceitual entre o "Estado", como portador abstrato [...]". (WEBER, 1999, p. 230)
} 
não é a felicidade no mundo sublunar, mas a beatitude em Deus. [...] o bem comum dos escolásticos tem a ver com a Cidade de Deus e inscreve-se na ordem divina", Laval; Dardot, 2017, p. 33).

Se não bastassem os riscos de estatizar ou de espiritualizar a noção de comum, Laval e Dardot vão além, e pretendem expor um cuidado que passa a ser fundamental para nossa metodologia, que é a "reificação". Alertando-nos, assim, contra o risco de inserir determinadas essências às coisas exteriores. Há uma confusão entre as coisas comuns (res communis) e as coisas inapropriáveis e sem dono (res nullius), sendo que no Direito Romano era sim possível que as coisas comuns tivessem usos ${ }^{6}$, enquanto e as inapropriáveis pudessem ser ocupadas.

Concluem os autores que há a necessidade de revisão do conceito de "patrimônio comum da humanidade", pois estaríamos, novamente, diante de uma ilusão naturalista. Além do fato de que a associação da natureza à noção de bem, e, por conseguinte, à noção de patrimônio pode causar problemas jurídicos, dos "quais o mais espinhoso é o de que todo patrimônio requer um sujeito" (LAVAL; DARDOT, 2017, p. 44). Em resumo, trata-se de uma incoerência jurídica a noção de patrimônio sem sujeito. Criticando a construção filosófica que vulgarizou a percepção de comum, os autores sintetizam essa nova perspectiva conceitual:

o comum não é nem a humanidade como essência moral ou dignidade [...], nem a humanidade como espécie [...], nem a humanidade como aptidão para simpatizar com os outros homens[...]. O comum deve ser pensado como co-atividade, e não como copertencimento, copropriedade ou copossessão. (LAVAL; DARDOT, 2017, p.52 grifos nossos)

Se por um lado o debate europeu sobre as acepções da noção de comum na modernidade podem ser criticadas, somaremos nessa (re)conceitualização os sintomas da integração subordinada do continente americano no que se convencionou chamar como "lado oculto da modernidade" (ALIMONDA, 2011). Ou seja, o lugar do desenvolvimento (a Europa e o Norte) foi estabelecido na medida em que foram ocultadas outras lógicas, como a racionalidade das formas estatais, a acumulação originária do capital, a apropriação da biodiversidade dos trópicos e a missão

\footnotetext{
${ }^{6}$ Citação do jurisconsulto Marciano, primeira metade do século III: "Umas, denominadas res nullius (coisas sem dono), são factualmente vacantes: têm propensão a pertencer ao primeiro ocupante que se apossar delas. São assim, por exemplo, os animais selvagens; As outras, denominadas res communes omnium, são coisas que, por natureza, não pertencem a ninguém e cujo uso é comum a todos. São elas o ar, a água corrente, o mar e a costa que se estende até onde chegam as águas das marés altas de inverno." (apud, LAVAL; DARDOT, p. 36)
} 
evangelizadora combinada com o eurocentrismo presente em nosso imaginário. A colonialidade é um complemento necessário para nossa reflexão.

Numa tentativa de compreender como populações subalternizadas se esforçam na luta cotidiana para garantir condições materiais e simbólicas de sua (re)produção, Raquel Gutiérrez Aguilar e Mina Lorena N. Trujillo (2019) investigam as práticas políticas de produção do comum. Colocam como elemento determinadas chaves metodológicas fundamentais: as ambiguidades do comum entre os seguimentos subalternizados; o comunitário como relação social que se produz, se pratica e se cultiva; a produção do comum como um modo coletivo de renovar e disputar a gestão; as lutas das mulheres em defesa da vida e contra as violências.

Tais elementos básicos colocados pelas autoras são tensionados a partir de processos reais de luta no continente americano. Evidenciando, assim, que as formas de acumulação capitalista correspondem a uma "galaxia de actividades y procesos materiales, emocionales y simbólicos" que não se realizam automaticamente como reprodução do capitalismo, ainda que ocorram subsunções, cercamentos, reduções e agressões. Diante disso, “quedan ocultos y son considerados 'anómalos' los procesos creativos y productivos que sostienen cotidianamente la vida humana y no humana" (AGUILAR; TRUJILLO, 2019, p. 300).

Esse grupo de trabalho com base no México (Benemérita Universidad Autónoma de Puebla), percebe a construção da noção de comum como garantia da (re)produção material e simbólica da vida coletiva, abrindo novos caminhos para a emancipação social contra duas lógicas centrais: a do Estado moderno e a do mercado. Para tanto, a reflexão se orienta para "entender siempre las multiformes $y$ heterogéneas luchas contra las separaciones, cercos y agresiones explícitas por los diversos y contemporáneos procesos de reconfiguración capitalista neoliberalcolonial, progresista o neofascista" (AGUILAR; TRUJILLO, 2019, p. 302).

As autoras elencam as quatro "síntesis parciales" para a discussão sobre a produção do comum: 1) o amálgama da dominação colonial-republicano-liberal e a exploração capitalista, estruturada no Estado-nação; 2) a estrutura da propriedade fundiária e suas relações do domínio; 3) os "renovados despojos múltiples" das riquezas materiais e capacidades políticas; 4) as formas canônicas de reprodução material da vida coletiva entrelaçadas com as relações patriarcais. A partir de vários exemplos de lutas pelo continente americano, e partindo de pressupostos da ecologia 
política para compreender os processos de cogestão da vida humana e não humana, assim definem um campo e nosso objeto em particular de reflexão:

Tales procesos de reconstitución hacen parte de una estrategia de defensa y cuidado de la trama comunitaria, de sus vínculos sociales y afectivos, así como del conjunto de creaciones que se comparten, gestionan y producen colectivamente. La producción de lo común es precisamente un proceso que organiza la interdependencia y los vínculos humanos y no humanos, poniendo en el centro la defensa y la afirmación de la vida. En medio de aquello que las separaciones y los procesos de despojo múltiple han buscado negar, erosionar, fragmentar o alterar, la producción de lo común es un ejercicio de reconexión, recomposición y reapropiación. (AGUILAR; TRUJILLO, 2019, p. 313)

\section{3- Primeira aparência do comum: a essencialização}

Há uma dupla concepção de construção de comum que se vincula à própria história da comunidade de Sebastião Lan II. Aparentemente distintas, ambas propostas chegaram de cima para baixo, e significaram restrições de acesso ao território. Enquanto a primeira expressão de construção do "comum" vinculava-se à ideia de ampliação da área da Reserva Biológica de Poço das Antas; a segunda expressão resulta de uma visão que chamaremos de "estatização do comum", de um projeto de assentamento e comunidade planejado pelo Incra.

Por situar-se ao lado de uma reserva biológica, o acampamento Sebastião Lan II tem seus conflitos socioambientais ligados à tensão entre os paradigmas da preservação ambiental e a agricultura. Por isso há, pelo menos, duas disputas pela imposição do que poderíamos chamar de uma noção de "bem comum". Primeiro, ao longo das décadas de 1980 e 1990, quando contemplávamos um conflito entre os grandes proprietários e os trabalhadores rurais. E, posteriormente, o conflito aparentemente (in)superável entre concepções de uso da terra, que envolvem dois órgãos do Estado, uma autarquia para reforma agrária e uma autarquia para preservação ambiental.

No território de Sebastião Lan II, após a vitória do movimento social e a conquista da terra, o Ministério Público Federal, o Ibama e ONGs ambientalistas promoveram duas Ações Civis Públicas (ACP). Isso resultou, em 1998, numa limitação do Incra em promover assentamentos rurais no entorno da Reserva Biológica. As ACPs visavam recompor danos morais e patrimoniais referentes às questões ambientais.

As denúncias e a ação de uma rede conservacionista, agenciadas pelo lbama e pela Associação do Mico-Leão-Dourado, iniciaram um processo de transformação de 
um conflito fundiário em um conflito ambiental. Tensionado, o MST promoveu discussões e alianças com setores do movimento ambientalista do Estado do Rio de Janeiro. Além do compromisso de reflorestar as áreas degradadas, o movimento se comprometia a não fazer uso de agrotóxicos, realizar estudos técnicos, respeitar a legislação ambiental e combater práticas predatórias, como o desmatamento e a caça. Entre os compromissos também constava a possibilidade de "garantir aos ambientalistas amplo acesso para comprovação dos cuidados ambientais"7.

Nesse cenário, aparece para os pesquisadores a possibilidade de construção de um acerto harmônico, quando se vislumbrava uma iniciativa no sentido de criar um projeto concreto de desenvolvimento sustentável para a constituição do assentamento Sebastião Lan II. O local é de interesse especial para a reprodução e expansão da reserva, além de servir como proteção ao entorno degradado pelas queimadas, pelo pasto e pelas monoculturas de arroz. Após duas décadas, a ocupação demonstrou uma recuperação produtiva do solo castigado, além de não interferir na reprodução do mico-leão-dourado e da fauna da reserva de forma positiva.

\subsection{O meio ambiente reificado}

O ano de 1974 é marcado pela a implementação da Reserva Biológica de Poço das Antas. A justificativa para a criação da reserva foi a preservação do micoleão-dourado, em consonância com os riscos ecológicos advindos da intensa degradação da Mata Atlântica.

Apesar de a criação da unidade de conservação ter ocorrido em 1974, os debates começaram com a Fundação Brasileira para a Conservação da Natureza, em 1968. Indicava-se, então, a importância dos primatas para a pesquisa biomédica e para a indústria farmacêutica (UFF, 2007). Matérias do Jornal do Brasil já anunciavam a desapropriação de áreas para a construção da Reserva desde 1970. Mesmo com a criação da unidade de conservação, a devastação continuava. Relatos de caçadores presos, o desmatamento e produção de carvão permanecem, mesmo após 1974.

Temos, nesse cenário, a constituição de uma noção de "comum" que pode ser relacionado a uma "essencialização", a um bem comum universal "inquestionável". $\mathrm{Na}$ medida em que se concebe um território apenas a partir do interesse da

\footnotetext{
${ }^{7}$ Pacto Chico Mendes, Rio de Janeiro, novembro de 1997.
} 
reprodução de uma espécie animal, a consequência lógica dessa essencialização é tornar secundária as implicações socioambientais de tal postura. Todas as ações institucionais mobilizaram entidades de setor privado (Ongs, empresas) e do setor público (órgãos do Estado) para um fim específico: a preservação ambiental. As manifestações desse paradigma representam, no caso em estudo, a ausência de seres humanos como destinatários dos projetos. Apesar de bem sucedida a ação (com o aumento das famílias de micos na Reserva), podemos associar a ideia de construção de uma Reserva Biológica sem presença humana como uma "essencialização" da natureza, como uma "essencialização" de uma fração do território e de uma espécie animal, e, por conseguinte, como uma reificação da ideia de "comum".

Em outra conjuntura, mais atual, ilustraremos variadas formas e consequências dessa essencialização. Os projetos para "rerruralizar" o território do Vale do São João nas décadas de 80 e 90 tem duas dinâmicas, uma pelos movimentos sociais e outra via os novos proprietários rurais, ou novos rurais. Esses últimos tem como traço comum reificações do meio ambiente como "bem comum" e/ou "mercadoria". De uma perspectiva dos proprietários de terras da região, sejam eles donos de sítios ou grandes proprietários, faz-se necessário tecer algumas linhas de reflexão sobre as suas novas formas de organização.

No calor da luta dos movimentos sociais pela reforma agrária, a preocupação dos fazendeiros em transformar Casimiro de Abreu e Silva Jardim em polos turísticos, apoiados pelo "fetiche" da Reserva Biológica de Poço da Antas, fez com que assistíssemos à proliferação das Reservas Particulares de Patrimônio Natural (RPPN) para proteção da Mata Atlântica. Exemplos coletados em conversas com proprietários de RPPNs já implantadas chamaram nossa atenção: um deles fez uma "cerca natural" em sua propriedade, ou seja, implantou a RPPN rodeando-a; o segundo fez uma RPPN em torno e próximo à casa principal da fazenda, protegendo a vegetação de suas caminhadas e preservando o canto dos pássaros "contra a ameaça" que representavam seus próprios filhos (sic); o terceiro, fez de sua propriedade inteira uma RPPN. Indagado pela equipe da UFF sobre como ele vive e o que faz, revelou ser morador da cidade do Rio de Janeiro, trabalhando com investidores internacionais, para a conservação da natureza. 
No ano 2000, através da Lei Federal n 9.985, as Reservas Particulares do Patrimônio Natural (RPPN) são classificadas como Unidades de Conservação. Hoje, no Brasil, existem, segundo o Instituto Chico Mendes, 672 RPPNs, sendo que 65 estão no Rio de Janeiro. Tramitava no Congresso um projeto de lei (PL 1.548/2015) que pretendia reduzir a taxa de juros do crédito agrícola para imóveis rurais com essa unidade de conservação, com um mínimo de 30\% dessa modalidade no imóvel. Esse projeto de lei permitiria a conversão de multas ambientais em serviços, bens e benfeitorias para as RPPNs, além da criação de um Fundo Nacional das RPPNs. Ou seja, pelo projeto de lei, torna-se possível transformar uma multa ambiental em benfeitorias realizadas na propriedade do infrator, nas áreas onde existe RPPN 8 .

Hoje há uma "Confederação Nacional das Reservas Particulares do Patrimônio Natural", como instância nacional de representação, associada às redes estaduais e regionais/municipais. Entre as conquistas noticiadas por essa organização está a transferência de recursos do ICMS ecológico para os proprietários. A possibilidade de captação de recursos públicos, de utilização de multas ambientais, de captação de recursos privados via compensação ambiental ou mesmo de políticas de responsabilidade social das empresas privadas ou multinacionais cria um cenário de oportunidade para os proprietários. MADEIRA FILHO (2008) já fazia indicações dessas novas possibilidades ${ }^{9}$.

Esse movimento das elites rurais indica que as "lideranças patronais rurais e agroindustriais" se mobilizam coletivamente em diversos espaços de representação política, de crédito agrícola e renegociações de dívidas (SEVA, 2008). Discute-se a influência do surgimento de movimentos sociais e organizações não governamentais, cujas críticas vêm incidindo diretamente no enfrentamento e posicionamento político em relação à questão ambiental (MADEIRA, 2002 e 2007, ACSELRAD, 2004), pela incorporação do debate a partir da lógica empresarial.

Essas "vantagens", previstas na legislação específica sobre as RPPNs, parecem, à primeira vista, enunciar uma reelaboração na legislação ambiental

\footnotetext{
${ }^{8}$ Projeto de lei arquivado em 31/01/2019. Nas eleições de 2018 a Confederação Nacional de Reservas Particulares do Patrimônio Natural lançou uma Carta Aberta aos candidatos buscando apoio.

9 "A RPPN S.A., além de consistir em um verdadeiro 'fundo verde' de aplicação [...] Tal iniciativa possui como elemento paradoxal valer-se da própria dinâmica do capital para incentivar um investimento em conservação ambiental [...] Esta ideia pode ser incorporada ao que Boltanski e Chiapello chamam de um "novo espírito do capitalismo". Os valores de responsabilidade e de solidariedade foram capturados da "crítica artística" produzida nos anos 1960 [...]". (MADEIRA FILHO, 2008, p. 19)
} 
contrária aos privilégios históricos das elites rurais, obtidos pelo domínio privado da terra. O que se poderia apontar como o diferencial deste momento atual, a partir da ideia de renda da natureza, proposta por Moreira (1995), seria uma nova roupagem da competição intercapitalista pela apropriação do conhecimento sobre a natureza.

Ao (re)discutirmos a figura do proprietário fundiário, identificamos novos processos de apropriação de saberes científicos e tecnológicos, eixos das inovações desses elementos-chave da dinâmica social, econômica e cultural da contemporaneidade. Moreira (1995) recupera a ideia de que esse processo está permeado pela presença de elementos renovadores, ou modernizantes. Assim, este proprietário é beneficiário de inúmeros investimentos públicos e privados realizados fora de sua propriedade, e a propriedade continua a ser o instrumento de apropriação privada do trabalho social e da natureza ${ }^{10}$.

Mas há que se fazer uma ressalva sobre a complexidade dos proprietários rurais, pois nem todos são herdeiros do latifúndio. Encontramos nos trabalhos de campo novos proprietários, que procuraram o mundo rural como alternativa de fuga do "barulho, das sirenes e da loucura urbana", procurando "um novo começo" ou um "elo espiritual com a natureza", frases recorrentes encontradas em pequenos sítios ou pousadas da região. Esse movimento, sintomático, pode ser enquadrado como a expressão da "nova" ruralidade (CARNEIRO, 2008).

Em resumo, estamos diante no Vale do São João de diferentes manifestações de uma natureza reificada e, por conseguinte, como expressões diferenciados de um "comum" que se tornou uma "essência" metafísica. Em consequência temos a percepção da natureza como não humana, e o humano como não natural - isolandoos (Diegues, 1996). Aqui vislumbramos a reificação de uma ideia de comum como se fosse autônoma e independente das relações sociais, um mito e também uma mercadoria.

\footnotetext{
10 "No contexto contemporâneo, a questão ecológica vai imprimindo novos significados à questão da propriedade da terra, redimensionando-a como valorização e apropriação da natureza. (...) A questão das florestas tropicais e a agricultura na Amazônia ganham um novo sentido na competição intercapitalista". (MOREIRA, 1995, p. 110)
} 


\section{4- A estatização do comum}

Em 1965, promulga-se decreto federal, visando à criação de uma zona prioritária de emergência para fins de reforma agrária, que compreendia uma visão "modernizante" do Vale do São João. Além de caracterizar-se como campo privilegiado de estudos, seu desenvolvimento, ao mesmo tempo em que representou uma expansão da fronteira agrícola fluminense, na década de 70, também promoveu a rearticulação das elites rurais com o capital especulativo imobiliário.

Houve, simultaneamente, a expropriação de pequenos posseiros da região e a combinação de grandes obras/devastação ambiental com a construção de ilhas de preservação ambiental. Essa "racionalização" também simbolizou uma nova integração. A presença dos antigos e novos fazendeiros do Vale do São João tornouse hegemônica, e os camponeses passaram a ser expulsos ou perderam suas terras. Obras e projetos acabaram se tornando um repositório de expropriação e violências, seja pelo cerceamento das atividades agrícolas e limitações ambientais, seja pela especulação imobiliária que ampliava suas fronteiras frente aos antigos posseiros, seja pelo "cercamento" do Vale do São João pelos grandes proprietários, que acabaram constituindo um território para latifundiários (RIBEIRO, 2007).

Duas décadas depois, uma ocupação em particular, organizada pelo MST e pela Fetag, merece destaque. Em 1997, os trabalhadores rurais ocuparam e construíram acampamento nas terras da Fazenda Sobara. Alguns ônibus passaram por cidades próximas coletando as famílias que originariam a primeira ocupação. Entre as cidades podemos citar, de acordo com os relatos: Silva Jardim, Cabo Frio, Araruama, Casimiro de Abreu, Rio das Ostras, Macaé, Conceição de Macabu e Cachoeiras de Macacu. Segundo relato coletado em 2017: "mandaram o ônibus no dia 20 de junho de 97, a noite juntamu todo mundo e viemos pra mundo a fora, sem saber pra onde ir. Viemos do lado de lá, viemos pela Amaral Peixoto. Entramos, quando foi de madrugada nós chegamos aqui” (acampado de Sebastião Lan II).

O entorno da Reserva Biológica foi não só alvo de um processo de grilagem de terras e disputas judiciais, mas também de uma reocupação pelo movimento social organizado, retornando a área para o domínio público através da gestão do Incra. Trata-se de uma outra dinâmica de rerruralização. A mobilização de trabalhadores 
pelo MST, Fetag e Sindicato de Trabalhadores Rurais de Cabo Frio culmina na reocupação de terras que "sobram" da implantação da unidade de conservação.

Dia 21 de junho de 1997, surge o primeiro acampamento onde hoje fica o Assentamento Sebastião Lan I, com a mobilização de cerca de 300 famílias. A escolha do nome representa uma homenagem à memória do ex-presidente do Sindicato dos Trabalhadores Rurais de Cabo Frio, liderança assassinada no atual Assentamento Rural Campos Novos (Cabo Frio). O Brejão (área do Sebastião Lan II) corresponde a uma área impactada pela retificação dos rios Aldeia Velha e São João, que separa os dois acampamentos homônimos.

Originalmente inundada, "um pântano" (segundo relato de antigos moradores), em que os processos de dragagem e drenagem permitiram sua exploração econômica. É uma área cujo solo de turfa emergiu das áreas de mata ciliar drenadas, rico em matéria orgânica. Com o fracasso do arroz e o uso depois pouco otimizado, é relevante citar o enorme passivo ambiental criado pela aliança entre os latifundiários e as políticas desenvolvimentistas.

Apesar dos percalços do caminho, em 23 de maio de 2005, um Termo de Ajustamento de Conduta (TAC) finalmente prevê a possibilidade da criação de projetos na área na modalidade Projeto de Desenvolvimento Sustentável (PDS). Mas há elementos polêmicos e dúbios entre os "considerandos" do TAC, como, por exemplo, a indicação de que as áreas ilegalmente desmatadas no entorno da Reserva Biológica não deixam de ser classificadas como de proteção permanente e não poderiam ser utilizadas com finalidades agrícolas. Ou seja, o TAC é contraditório em si mesmo, pois, ao mesmo tempo em que diz ser viável um assentamento numa área ilegalmente desmatada por um grileiro, afirma serem proibidos assentamentos em áreas ilegalmente desmatadas.

Sobre as cláusulas do termo, há outros pontos polêmicos: clausula segunda, "acordam assim as partes a respeito da possibilidade teórica de existirem projetos de assentamentos rurais, implantados pelo Incra dentro do raio de $10 \mathrm{~km}$ do entorno da REBIO de Poço das Antas". O que é uma possibilidade teórica? Na cláusula terceira, o Incra deveria considerar não aproveitáveis as áreas (APP e de Reserva Legal) de efetiva preservação ambiental. Essa terceira clausula entra em contradição com o próprio Código Florestal, que permite o aproveitamento diferenciado da Reserva Legal (item que causará grande repercussão sobre as restrições de uso). 
Em dezembro de 2014, o INCRA publicou uma portaria criando o Projeto de Desenvolvimento Sustentável (PDS) Sebastião Lan II, com a capacidade de abrigar 44 famílias. Para os acampados, essa nova versão da presença do Estado torna-se uma fonte de conflitos, haja vista que a atuação do Incra passa a ser pautada pela defesa quase intransigente da preservação ambiental.

Bases para a publicação da Portaria do Incra que criou o PDS Sebastião Lan II, a Licença Prévia e a Nota Técnica, desconsideraram as duas décadas de experiência humana e a sua relação com a terra. Os moradores temiam a possibilidade de despejo e a possível demolição de uma infraestrutura a duras penas construída (casas, uma Igreja e a sede da Associação).

As famílias não foram contempladas nos estudos prévios como autoras do processo, mas sim como famílias a serem inseridas em um projeto aparentemente não existente. Esse pressuposto resultou em enormes problemas técnico- políticos decorrentes dessa contradição. Enquanto, por exemplo, a Licença Prévia (LP) exigiu "não iniciar qualquer atividade antes das licenças de instalação e de operação", desconhecia-se o fato de que a comunidade já existia e praticava agricultura e criações há cerca de duas décadas.

Pelo novo assentamento, a área da reserva legal chegaria a 999,14 ha, muito acima do exigido pela legislação. Outro ponto chamava a atenção: o fato de a LP exigir o início de um "Plano de Restauração Florestal das APPs e RL até um ano depois da sua aprovação". Esse último elemento, além de desconsiderar toda a experiência da comunidade, impõe uma relação entre o homem e o meio ambiente que resgata o mito da natureza intocada (DIEGUES, 1996), na medida em que não se reconhece a possibilidade de convivência harmoniosa entre a agricultura e a conservação. Nessa linha de raciocínio, restaurar não é sinônimo de conservar, mas significa, antes de tudo, a recuperação de uma natureza anterior à interferência do ser humano, o que, na prática, significaria transformar mais da metade do assentamento em um brejo/pântano novamente.

A necessidade de realizar uma nota técnica que fosse aprovada por órgãos ambientais, possivelmente, orientou a formulação de um projeto de assentamento com um viés menos produtivista. $O$ debate, por parte da comunidade, entende que essa perspectiva não só atende as demandas dos preservacionistas, mas também impede o desenvolvimento de qualquer agricultura minimamente sustentável. 
A permanência deste grupo de ocupantes já perfazendo duas décadas na área em foco, exigiria, previamente, a consideração sobre a construção das casas para moradia, assim como o investimento realizado (conforme previsto em estudos e documentos preexistentes). Segundo os moradores essa "falta de respeito pelo que construímos dificulta a conversa". Como contrapartida à exigência de uma agrovila e à criação de uma grande área de uso coletivo, a comunidade oferece um outro ordenamento territorial, mas que não desloque os lotes já historicamente habitados.

Há uma contradição entre o modelo de PDS, com exploração coletiva, e a tradição agrícola de loteamentos individuais, seja para a produção, seja para plantios de subsistência. Ressaltando o fato de que a área encontra-se já com benfeitorias tais como casas de farinha, galpões de produção, igrejas e demais investimentos individuais nos respectivos lotes.

Houve uma repulsa da comunidade à proposta, calcada na estruturação de uma produção coletiva inexistente, numa área maior do que a área a ser destinada para os lotes individuais. Ocorre que a comunidade já se organizou em lotes individuais, havendo uma grande rejeição por uma forma coletiva de organizar a produção e as moradias. Sobre a possibilidades de concentrar coletivamente as moradias, os trabalhadores rurais diziam: "eu não quero ouvir meu vizinho", "quero ficar onde estou", "vai parecer uma favela" - reclamações comuns.

Nos referimos a esse processo como estatização do comum na medida em que há uma imposição de lógicas e racionalidades estranhas à comunidade. A adaptação de um modelo originariamente destinado a cumprir finalidades específicas para a região Norte do Brasil (o PDS), torna-se um desafio para o Incra do Rio de Janeiro, principalmente pelo fato de essa experiência acontecer simultaneamente em dois contextos territoriais diferentes. De um lado, o projeto de PDS Oswaldo de Oliveira, uma terra desabitada na qual o Incra deveria inserir os beneficiários da reforma agrária nos moldes do PDS. E, de outro lado, o projeto de PDS Sebastião Lan II, no qual já existia uma comunidade que precisava ser assentada e ter sua terra e produção regularizadas. Duas dinâmicas diferentes, dois trabalhos que desafiavam o modo tradicional de se fazer reforma agrária em terras fluminenses. 


\section{5- O sapê: um comum como co-atividade}

A classificação dos lotes pelas lideranças da comunidade de Sebastião Lan II, sob coordenação do OBFF/GT Ecosocial, diferenciou-se da metodologia utilizada pelo Incra. Em reunião realizada com membros das últimas duas gestões da Associação de agricultores de Sebastião Lan II, observou-se como o caráter de liminaridade sociojurídica vivenciada há 20 anos obrigou-os a receber novos membros como condição de sobrevivência, para a manutenção do tecido social e o fortalecimento da produção interna.

Esse ingresso de trabalhadores rurais somou-se a uma dinâmica de saída e retorno, seja por motivos econômicos, seja por motivos familiares (separações, mortes, nascimentos), o que caracteriza uma demanda constante por mobilidade (externa ou interna). Mas essas dinâmicas tem que ser combinadas com a defesa contra as invasões do território, seja por fazendeiros ou por grupos de especuladores urbanos. Ou seja, tanto a pesquisa quanto as conversas com as lideranças demonstraram o quanto é "preconceituosa" ou "etnocêntrica" a perspectiva de fixação do homem no campo.

Qual o tipo de homem que deve ser "fixado" no campo? Como construir modelos capazes de "inserir" indivíduos em lotes para serem beneficiados pela reforma agrária? Como identificar o potencial de um trabalhador rural ou de periferias urbanas que se pretende um agricultor familiar? A mobilidade interna ou externa dos trabalhadores rurais significa apenas uma especulação da terra? As diversas práticas de mobilidade seriam indícios de uma falta de uma "cultura" coletiva?

A fala e o discurso ao mesmo tempo revelam, condenam e censuram elementos do passado e do presente. Trata-se de idiossincrasias que caracterizam cada campo em disputa. Assim, o poder de classificar, reelaborar a memória coletiva, coloca em jogo formas de exercício de poder em suas diversas dimensões (econômica, simbólica ou políticas). Para Pierre Bourdieu (2005), a relação do sujeito com o seu passado envolve uma reconstrução permanente da história, que se relaciona com os seus aliados e adversários do presente. Ou seja, as classificações estão intimamente relacionadas com os campos de disputa.

A complexidade da classificação interna começou a aparecer quando as lideranças resolveram criar uma categoria para incorporar diferentes situações de 
ingresso em Sebastião Lan II, posteriores à ocupação de 1997. Trata-se da classificação como membros da comunidade. São pessoas e famílias que obtiveram uma aprovação formal, em assembleia, ou ingressaram em acordo com o último ocupante do lote, seja ele participante da ocupação original ou não. São pessoas que, de certa forma, entraram de forma "amigável" e contribuem com as redes de solidariedade internas. Essas redes internas podem ser percebidas tanto nos desafios da produção (dividindo insumos, equipamentos), como no suporte para as mobilizações de reivindicação nos órgãos públicos, apoiando outros membros em momentos difíceis (durante as enchentes, doenças ou transporte) e, também, nas atividades festivas ou religiosas.

Podemos citar exemplos. Um "membro da comunidade" que se deslocou de lote internamente, por temor das enchentes. Em outra situação, uma família considerada "não produtiva" (de acordo com relatórios do Incra), com a qual conversamos e identificamos também um apoio coletivo para a sua permanência em Sebastião Lan II, que havia ingressado inicialmente na área do Sapê. Diante das dificuldades encontradas inicialmente, decidiram, com o apoio da comunidade, deslocar-se para um lote de melhor qualidade.

Enquanto para o pesquisador do Incra as classificações de "ocupante" e de “ocupante não produtivo" referem-se a pessoas que não moram em Sebastião Lan, pode-se perceber que esse critério é relativizado, tanto para a instituição de reforma agrária quanto pela comunidade. A aceitação da família ou do trabalhador rural como "morador" refere-se à luta inicial para conquista da terra, ao direito conquistado para vendê-la e receber a devida renda da terra, ao investimento realizado no lote, ao direito conquistado em votações internas (assembleias) para aprovação do seu nome.

Mas a entrada de novos moradores não é simples, ela acontece através de um tipo de "laboratório". Assim, tanto a mobilidade dos trabalhadores quanto a sua vontade em manter o parcelamento individual dos lotes (frentes às lógicas coletivistas) eram classificadas por órgãos do Estado como uma "falta de cultura" ou como uma "zona de conforto" que precisava ser mudado. Trata-se de uma racionalidade própria de uma lógica de sobrevivência que era vista como uma negação à ideia de "fixação do homem à terra".

Podemos fazer uma analogia da situação de Sebastião Lan II à noção de mobilidade espacial, caracterizada por Félix (2009) como característica de reprodução 
do campesinato. A possibilidade de incorporar a terra como poupança ou recurso para investimento em outras áreas, ou até mesmo para garantia de uma residência em áreas urbanas na proximidade da velhice, torna-se não um critério para desqualificálos como irracionais, sem cultura coletiva ou especuladores. Mas, sim, para perceber a mobilidade como uma característica de um campesinato que percebe a fixação como uma imposição e limite de acesso a outros bens econômicos ou culturais ${ }^{11}$.

Esse laboratório pode ser exemplificado através de um morador respeitado tanto pelo Incra quanto pela comunidade. Ele foi antigo arrendatário de terra do grileiro e, após algumas brigas com o suposto dono da área, saiu da região. Após a conquista da terra pelo movimento social, ele retorna, e inicia um plantio na área conhecida como Sapê. Como o terreno apresentava problemas recorrentes de inundação e por causa da qualidade da terra, o morador inicia negociações para trocar de lote. A troca ocorreu, mediante uma negociação em que a pessoa que ficou no pior lote recebeu, em troca, um pequeno trator. Independentemente do reconhecimento da qualidade de seu trabalho agrícola, apesar de não residir - nem nunca ter residido - em Sebastião Lan II, para a comunidade e para o Incra, ele é classificado como morador. O que demonstra, até para órgãos do Estado, um reconhecimento fundamental sobre a necessidade de relativização de preceitos jurídicos absolutos.

Outro caso refere-se a uma família que ingressou, na área conhecida como Sapê, em 1999. Depois de dois anos tentando trabalhar a terra, com as devidas experimentações, seja do ponto de vista produtivo, seja do ponto de vista social, eles receberam o reconhecimento da comunidade de que mereciam uma terra melhor. Vindos de Cabo Frio, houve uma venda não autorizada de lote para um médico da cidade de Casimiro de Abreu, já configurando uma ocupação da área para fins exclusivos de especulação. Em assembleia, a comunidade decidiu que tal área seria melhor aproveitada se essa família de Cabo Frio a ocupasse. Esse conflito foi relatado pelos próprios pesquisadores do Incra:

\footnotetext{
11“a suposição de que estes camponeses necessariamente constroem projetos de fixação quando se veem numa situação de acesso a terra seria uma suposição que não leva em conta os próprios projetos idealizados pelo agente a quem se credita esta imobilização. O acesso a terra é apenas uma das condições necessárias para se constituírem como pequenos produtores e, sendo assim, como tantas outras que eles devem manejar visando adquirir todas as demais, a terra pode vir a ser um meio, por exemplo, de adquirir outra terra, e conseguir algumas cabeças de gado, de ter vizinhos conhecidos, de solucionar conflitos com fazendeiros, de montar um açougue ou de comprar uma casa na rua." (FELIX, 2009, p. 260)
} 
A associação transferiu sua posse para esse lote [...], os quais, à época, estava em mãos de um certo Dr. Y, conhecido médico ortopedista em Casimiro de Abreu. A posse deu-se em situação de conflito [...] completados os primeiros 15 dias de posse, o $\mathrm{Dr}$. Y retornou trazendo uma kombi lotada de pessoas (comparsas e/ou policiais) para retomar o lote. Estavam armados. Em meio ao desespero com a negociação fortuita e antevendo o pior, o casal procurou ganhar tempo enquanto [...] ligava para a diretoria da Associação, a qual reuniu os moradores do acampamento num carro para, juntos, oferecerem resistência aos componentes do bando." (INCRA, 2012, p. 194)

Casos como esses, envolvendo momentos de tensão entre moradores e especuladores de terra ilegítimos são comuns, relatados em reuniões tanto no Incra quanto na comunidade de Sebastião Lan II. Ainda que exista a possibilidade socialmente aceita de receber a renda da terra através da venda do seu lote, esse processo exige um comprometimento comunitário, uma relação de reciprocidade com o coletivo.

Em mais um exemplo, um morador novo de Sebastião Lan II ficou seis anos na área do Sapê. Esse tempo de trabalho foi fundamental para que ele obtivesse da comunidade, reunida em assembleia, a aprovação para se deslocar para um lote melhor, que acabava de ser abandonado. O processo de adaptação da vida em Sebastião Lan não é imediato, ou seja, o trabalhador rural precisa de um tempo para conhecer e ser reconhecido no território, precisa de uma convivência mínima com os membros da comunidade.

As pistas encontradas e a abundância de relatos de moradia e trabalho como experiência e laboratório numa área específica de Sebastião Lan II (o Sapê) indicou, durante a pesquisa, uma função social sui generis. Assim, podemos dizer preliminarmente que a área de Sapê funciona como uma espécie de laboratório experimental, exercendo as funções sociais de avaliação, adaptação, experiência, convivência e ingresso. Tratava-se de um recurso controverso para os técnicos do Incra, sem um estatuto legal próprio e sem que as autoridades fossem devidamente comunicadas.

Nos mapas mais antigos construídos pelos próprios moradores, em especial durante a Oficina de Cartografia Social, organizada pelo OBFF em 2008, essa área constava como Reserva Legal, a ser construída no momento da regularização fundiária do assentamento. Mas essa área de reserva não estava cadastrada como tal, a comunidade continuava sem a devida regularização, os moradores envelheciam 
rapidamente, outros saíam e a ameaça de reocupação da área por especuladores de terras era cada vez maior. Assim, a primeira gestão da Associação de Sebastião Lan II resolveu utilizar essa área como espaço de ingresso de novos moradores, fato revelador de que o movimento social começou a preencher uma lacuna deixada pelo Estado na gestão do território.

Como a área do Sapê estava descrita pela Associação como Reserva Legal, o pesquisador do Incra deixou de cobrir uma grande extensão de terrenos em suas pesquisas. Uma área que mais tarde seria reivindicada pela mesma Associação como um "nítido erro" nos mapeamentos realizados pelo Instituto, erro esse que devemos relativizar diante da situação de liminaridade da população. Essas ausências nos relatórios de ocupação de Sebastião Lan II foram, aparentemente, induzidas pela própria condição precária desses novos moradores em situação de ingresso. E, também, esse "suposto erro" do técnico do Incra em relação à área de Sapê, provavelmente foi induzido pelos moradores para manter esse espaço como área "comum", sob a lógica da comunidade e não da burocracia estatal.

Essa indução ao erro pode ser visualizada no momento de instalação da rede elétrica em Sebastião Lan II, pois os moradores do Sapê não foram contemplados. Trata-se da única área sem luz elétrica na comunidade. Nas últimas enchentes, ocorridas no início de 2018, eles foram as principais vítimas. Há um cuidado da Associação em encaminhar a ajuda e as doações para suporte dessas famílias. Assim como a incorporação dos moradores do Sapê no projeto final de assentamento passou a ser pauta inquestionável das lideranças.

$\mathrm{Na}$ área do Sapê, anteriormente classificada como improdutiva, a comunidade rural desenvolveu técnicas de convívio com o tipo específico de solo e, também, com a sazonalidade das enchentes. Ou seja, é uma área com potencial agrícola, mas que exige uma maior habilidade do que outras áreas da mesma comunidade rural. Eis que esse teste de perseverança, de solidariedade e de aptidão agrícola toma a forma de um laboratório experimental e de "exército de reserva" de famílias para fins de manutenção do tecido social de Sebastião Lan II. Assim, podemos considerar que o processo de classificação dos moradores da comunidade evidencia formas ocultadas de uma presença que não poderia ser notada, à margem de um Estado e à margem de uma lógica de mercado. 


\section{6- Considerações finais}

Eu queria saber do superintendente que vem responder. O porquê essa seleção não foi selecionada? (morador de Sebastião Lan II, 2013)

Como selecionar uma seleção? Poderíamos deduzir que "selecionar a seleção" refere-se à trajetória até a composição do atual formato dos ocupantes de Sebastião Lan II. Ou seja, houve já uma seleção dos ocupantes através da resistência física e política daqueles que insistem e lutam pela reforma agrária. A sobrevivência à seleção de uma luta social contra o desemprego, contra a vida precária nas periferias que unificou o primeiro grupo de ocupação. Em seguida, podemos encontrar a seleção diante da ausência de recursos essenciais do Estado, como transporte, lixo, educação, saúde, assistência técnica. E, também, a seleção provocada pelas inundações, o fogo, os tiros, e os constrangimentos de "autoridades" ambientais, policiais, científicas e jurídicas. E, por fim, a pergunta, o "porque essa seleção não foi selecionada?".

A velocidade de transformação de uma ocupação não permitiu que os estudos técnicos e científicos fossem "aprovados" num ritual democrático, nem a incorporação das experiências emergentes do "comum". Diante da entrada de novos ocupantes, as lideranças precisavam defender todos aqueles que ocuparam o território em 1997, muitos dos quais foram obrigados a sair por problemas econômicos, familiares e de saúde, só retornando a partir de um segundo momento.

Esse dinamismo foi a base de um questionamento de Dilce, sobre qual seria o perfil de agricultor para o Incra. A agricultora queria saber por que seu próprio nome não estava contemplado. Se, por um motivo de separação conjugal, foi obrigada a se ausentar do lote e, posteriormente, retornar. No caso, a noção de mobilidade social, separação, implicou afastamento temporário do território. Ela não constava na lista oficial sobre um "perfil apto" para ingressar na lista de beneficiários. A resposta a essa indagação criou outra cena de indignação, quando o técnico do Incra questionou: “Então, indiquem quem tem e quem não tem e o perfil”. A resposta de Dilce foi imediata: "Nós fizemos o papel do Estado, proibimos a venda de lotes e aí começamos a ser ameaçados". 
Nos últimos contatos com a Dilce, ouvimos relatos e dúvidas de como as assimetrias do mercado de terras, assim como a presença de intermediários ou donos de comércio local apareceram em Sebastião Lan II poderiam colocar em risco a construção em curso de um território "comum". Mas, de outro lado, os ocupantes irregulares (comerciantes locais e especuladores de terra) não se sentiam obrigados às mesmas relações de reciprocidade. Mas o movimento constante, de entrada $e$ saída de ocupantes, aparece, paradoxalmente, como uma forma de oxigenação da comunidade, mesmo que esse oxigênio seja carregado das impurezas, distorções e desigualdades do próprio território do Vale do São João.

Eis que a partir de um estudo de caso, em Sebastião Lan II podemos contemplar as ambiguidades como base epistemológica (CHAUI, 2014) para apreensão e reelaboração teórica da experiência da noção de "comum". Queremos dizer, trabalhar com o princípio de que as lógicas estatais ou do mercado representam, exclusivamente, princípios universais validadores das relações sociais, significa esterilizar as ambiguidades características de uma tensão entre autoritarismos e resistências democráticas.

Nos interstícios do Estado, nas sombras da legislação ambiental, na penumbra do produtivismo, há uma reforma agrária em gestação constante de novas noções do que é comum. A indignação de Dilce foi uma força, coragem e esperança de uma mulher que mostrou para todos nós os desafios de um território não mercantilizado, não patriarcal e não autoritário. A sua generosidade e sonho de viver com dignidade num território que é "de tod@s". Pois lá plantou raízes na terra e raízes aéreas. Sua vida continua, mesmo com a sua morte física em 2019, sempre saberemos que em Sebastião Lan II: Dilce está presente!

A releitura dessa luta através da noção de comum permite-nos questionar a suposta ilegalidade da ocupação original e depois a incompatibilidade entre a agricultura e o meio ambiente como as duas faces de uma mesma moeda: a estatização e a essencialização. Nesse período recente apareceu a falsa ideia de falta de aptidão do solo e de reengenharia de conjunto, reificações que fazem pouca diferença num contexto validador da exclusão permanente dos trabalhadores rurais. De uma forma ou de outra, todos os discursos técnicos, possivelmente racionais ou lógicos, foram prejulgamentos, que, uma vez aceitos, constituíram um a priori empírico que não pode ser transcendido. Mas, a partir de uma criatividade dos movimentos 
sociais em direção à preservação de um tecido social, afirma-se a manutenção da resistência para acesso à terra e ao trabalho como "co-atividade".

\section{Referências}

ACSELRAD, H. (org.) Conflitos ambientais no Brasil. Rio de Janeiro: Relume Dumará: Fundação Heinrich Böll, 2004.

AGUILAR, R. G.; TRUJILLO, M. L. N. Producir lo común para sostener y transformar la vida: algunas reflexiones desde la clave de la interdependencia. In: Revista Confluências, vol. 21, n² Niterói: Editora PPGSD-UFF, p. 298-324, ago. 2019

ALIMONDA, H. (Coordenador). La colonialidad de la naturaleza. Una aproximación a la Ecología Política Latinoamericana. Buenos Aires: CLACSO, 2011.

BOURDIEU, P. O Poder Simbólico. Rio de Janeiro: Bertrand Brasil, 2005.

BRANDÃO, C.R. (org). Pesquisa Participante. Ed. Brasiliense, SP, 3. Edição, 1981.

CARNEIRO, M.J. "Rural" como categoria de pensamento. Ruris, vol. 2, n.1, p. 9-38, mar. 2008.

CHAUI, M. Conformismo e resistência. São Paulo: Ed. Fundação Perseu Abramo, 2014.

DARDOT, P.; LAVAL, C. Comum: ensaio sobre a revolução no século XXI. São Paulo: Boitempo, 2017.

DIEGUES, A. C. O Mito da Natureza Intocada. São Paulo: Ed. Hucitec, 1996.

FELIX, G. A. Os vira-mundos e a condição camponesa. IN: NEVES, D. P. (Org.). Processos de constituição e reprodução do campesinato no Brasil, v.2. São Paulo: Editora UNESP; Brasília, Núcleo de Estudos Agrários e Desenvolvimento Rural, 2009. INCRA, 2012.

LOBATO DA COSTA, R. B. M. Estudo de Caso sobre o Acampamento dos Sem Terra Sebastião Lan II nas bordas da Rebio de Poço das Antas (RJ): formas de não realização da reforma agrária. Doutorado. Tese, Universidade Federal Fluminense, 2018.

MADEIRA FILHO, W.; MOREIRA; E. M. Como ir e vir sem sair do lugar: a história do TAC. IN: UFF, 2007.

MADEIRA FILHO, W. RPPN S.A.: uma estratégia liberal paradoxal. XVII CONGRESSO CONPEDI, 2008. 
MADEIRA FILHO, W. Teoria do contraponto: práticas e discursos sobre Justiça Ambiental. In: MADEIRA FILHO. Wilson (org.). Direito e Justiça Ambiental. Niterói: PPGSD/UFF, 2002.

MARTINS, J. S.. Caminhada no chão da noite. Emancipação política e libertação nos movimentos sociais no campo. São Paulo: Editora Hucitec, 1989.

MARX, K. Crítica da Filosofia do Direito de Hegel. Lisboa: Editorial Presença, s/d.

MOREIRA, R. J. Renda da natureza e territorialização do capital: reinterpretando a renda da terra na competição intercapitalista. Sociedade e Agricultura, n. 4. p. 89111, jul. 1995.

RIBEIRO, A. M. M. Reflexões metodológicas: a produção do laudo multidisciplinar sobre conflito agrário ambiental no entorno da rebio poço das antas - uma abordagem marxista. Associação Nacional de História - Boletim da ANPUH, 2007.

SEVA, J. T. Classes patronais rurais e conflitos sociais: Um estudo sobre as ações das organizações patronais rurais frente à questão ambiental. Dissertação, Universidade Federal Rural do Rio de Janeiro, 2008.

UNIVERSIDADE FEDERAL FLUMINENSE. 2007. Laudo multidisciplinar em conflito sócio-ambiental: o caso da reforma agrária no entorno da Reserva Biológica de Poço das Antas. Wilson Madeira Filho, Ana Maria Motta Ribeiro, Mônica Cox de Britto Pereira, Dario de Andrade Prata Filho (coordenadores). Série Pesquisas no2. Niterói: PPGSD-UFF.

WEBER, Max. Economia e sociedade: fundamentos da sociologia compreensiva. Volume 2. Brasília: Editora Universidade de Brasília: São Paulo: Imprensa Oficial do Estado de São Paulo, 1999. 